University for Business and Technology in Kosovo

UBT Knowledge Center

Oct 27th, 1:30 PM - 3:00 PM

\title{
A factor model for DCF valuation and application to the five largest banks in Bulgaria
}

\author{
Elena Ralinska \\ University of National and World Economy, e.ralinska@yahoo.com
}

Follow this and additional works at: https://knowledgecenter.ubt-uni.net/conference

\section{Recommended Citation}

Ralinska, Elena, "A factor model for DCF valuation and application to the five largest banks in Bulgaria" (2018). UBT International Conference. 274.

https://knowledgecenter.ubt-uni.net/conference/2018/all-events/274

This Event is brought to you for free and open access by the Publication and Journals at UBT Knowledge Center. It has been accepted for inclusion in UBT International Conference by an authorized administrator of UBT Knowledge Center. For more information, please contact knowledge.center@ubt-uni.net. 


\title{
A Factor Model for DCF Valuation and its Application to the Five Largest Banks in Bulgaria
}

\author{
Elena Ralinska, Ph.D. \\ University of National and World Economy, Sofia 1800, Bulgaria \\ e.ralinska@yahoo.com
}

\begin{abstract}
An existing factor model for valuing banks from the point of view of an outside observer is applied and the importance of the main factors defining value are assessed and their importance analyzed. The banks are explicitly modeled for a future period, based on the trends, returns and balance sheet proportions derived from their historically published statements. Assumptions are then made, incorporating information about the economic cycle, the policy of the central bank and ECB. The objective is to calibrate, apply and assess the behavior of a model which can then be used to stochastically stress test the banks under review. The procedure is independent from the one used and recommended by the public monetary authorities and intends to enrich the set of tools available to both academics and practitioners.
\end{abstract}

Keywords: Bank valuation, DCF, Value Factors, Factor Model. 


\section{Brief Description of Model and Scope of its Application}

The objective is to apply and assess the appropriateness, performance and ultimately the accuracy of an adapted income approach (DCF) model for the valuation of banks from the point of view of an outside observer.

The model is an adaptation of the Copeland (2002) valuation model developed and specified by Sarastov (2016) for banks. The ability of the model to perform is important as it represents the basis for subsequent stochastic stress-testing through Monte Carlo approach. Two important condition have to be fulfilled: (1) defining adequate structure of the model and internal factor relations and (2) suitable specification of parameters. The task is complicated as the two conditions cannot be separated while tested.

The key relation in the model is that the value of a bank equity essentially depends on the evolution of its free income to equity holders after all fiscal and capital adequacy charges. This income is decomposed into the key factors that drive it. The main assumption is that one can better analyze and forecast the factors than the resulting free income. The drivers identified and formulated quantitively by Sarastov et al (2016) are (1) the growth of the bond and loan portfolio, (2) its returns, (3) the evolution of the core deposit base and other funding portfolio, (5) its interest costs, (6) the non-interest fees rates (7) the value-charges from loan-loss provisions and credit events (6) the bank running costs and the capital adequacy charges. Analyzing the factors, we can group them in three separate sets. The first comprises the factors related to the size of the operations and their structure. The second consists of parameters related to interest rates and fees. The third set of factors is risk related. Therefore, tasks is hence reduced to analyzing the size evolution, the proportions within the size of a bank and how this relates to the returns this scale generates.

The model is applied for the 5 largest banks in Bulgaria that form Group 1 of systemically important institutions. In the beginning of 2018, UBB merged with EIB. The forecasts for that entity is on post-combination basis. The historical figures used are the combined ones as if the banks were a single entity safe for any synergies which are otherwise adjusted for in the forecasts. The historical data used to arrive at growth rates, proportions and returns is based on the annual reports for the period 2007-2017 published by the Bulgarian National Bank. The reported positions are adjusted for odd and extraordinary events. Most of the numbers of limited material significance are aggregated and mapped into the respective factors as discussed above. Due to limited space the data set is not published but available from the author upon request.

\section{Review of the Main Value-Driving Factors}

According to the applied model income and ultimately value of banks depends mainly on two factors (a) sales of their products and services and (b) the expected operating results from such sales. The latter includes net interest profit, net non-interest profit from fees and commissions but also importantly devaluation of assets and losses provisions. Sales of banks services are reflected mainly through the balance sheet, where deposits and loans end being recorded. The factor relations and dependencies are 
represented in Sarastov, 2016. The deposits determine the capital requirement that are subtracted from net income attributable to shareholders. The free cash flows together with the discount rate (risk) determine the value of equity capital. These relations and their structuring represent an adaptation of the factor model of Koller, Goedhart, Wessels (2010 p.10). We treat the debt resources raised as a supply, used for the production of loans and other interest (income) bearing assets. The integrated effect from the simultaneous performance of all factors can be reduced to two main factors, that determine the value of a bank, the first one being the growth of the deposits and debt sources and the second being the effective net return on them. We can assume that all else is determined by these two factors including the required equity capital.

\subsection{Growth of Income and Cost Generating Balance Sheet Positions}

Following the logic outlined above we study the evolution of (a) the loan and bonds portfolio of the banks, (b) the evolution of their deposit base. These two factors more or less determine the size of the bank, its profitability and affect value.

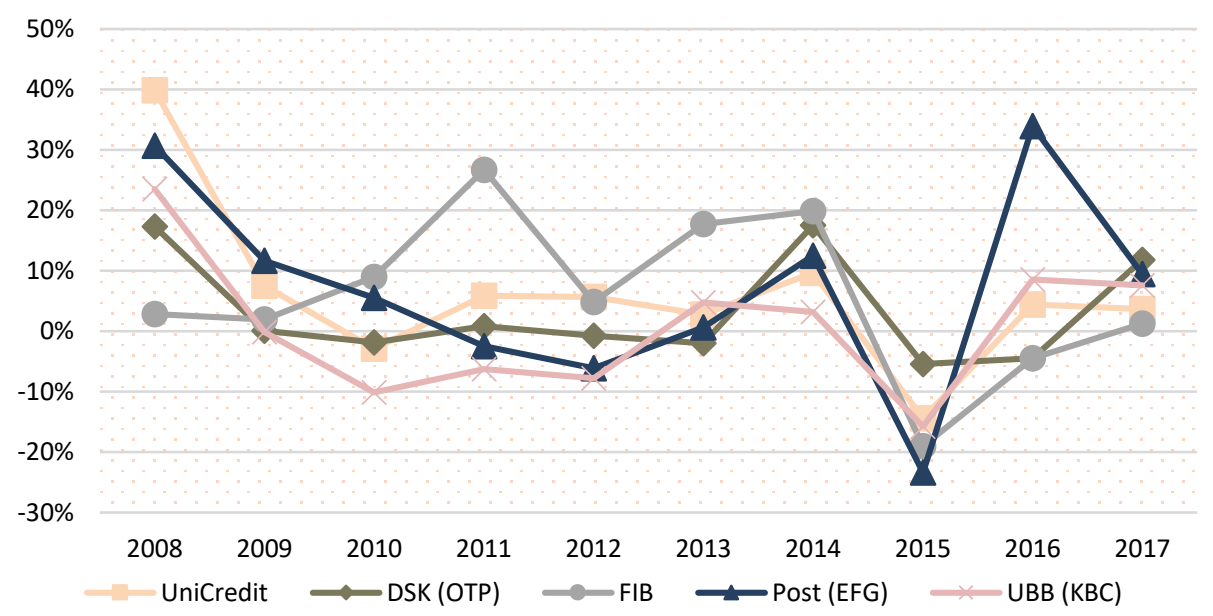

Fig. 1. Dynamics of the loan portfolio of banks

The loan portfolio dynamics reflects both the growth of GDP and the Confidence indices. The post global crisis (2008-2010) decrease of lending activity is well pronounced on Fig.1. A stabilization period follows till 2014 when a local mini bank crisis temporarily decreased confidence in the Bulgarian Economy. 


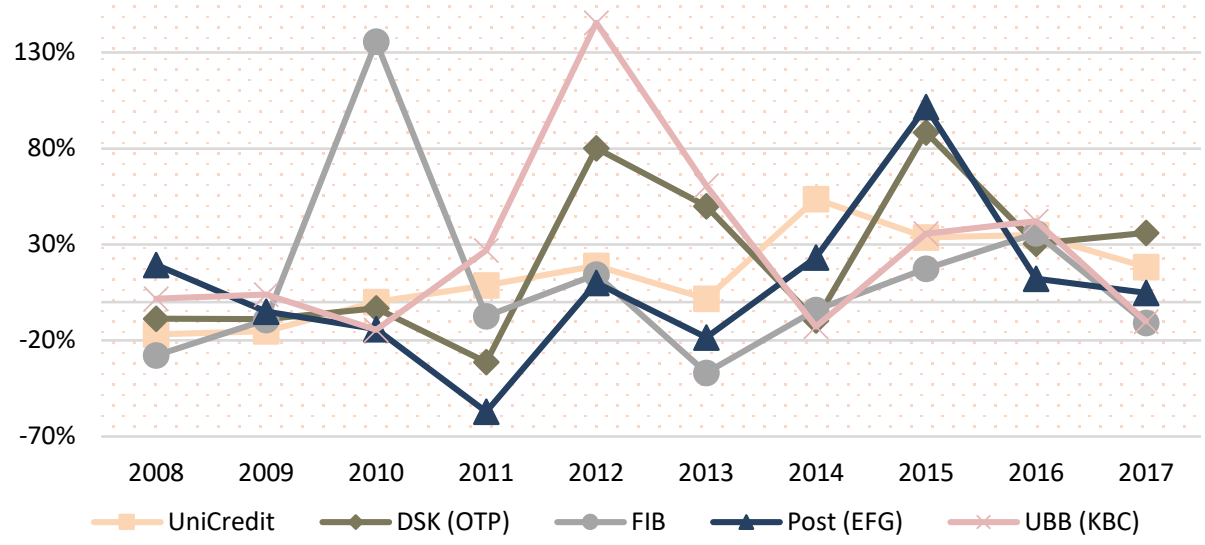

Fig. 2. Dynamics of the bond portfolio of banks

The dynamic of bonds is different from that of loans. Bulgarian banks view bonds mainly as a treasury management instrument and a temporary store of excess liquidity. As evident from the figure there are big differences between bond portfolio dynamics on an annual base, reaching above $100 \%$ in some periods. It is a great challenge to forecast the bond portfolio dynamics but as a rule the funds that are not placed as loans end up in the bond portfolio safe for minimum levels defined by bank liquidity policies.

Banks in Bulgaria are considered as a safe heaven by both households and SMEs due to the deposit guarantee as most deposits fall within the guaranteed $100 \mathrm{~K}$ euro ceiling. Therefore, the deposit base grows in line with GDP but also in low confidence periods.

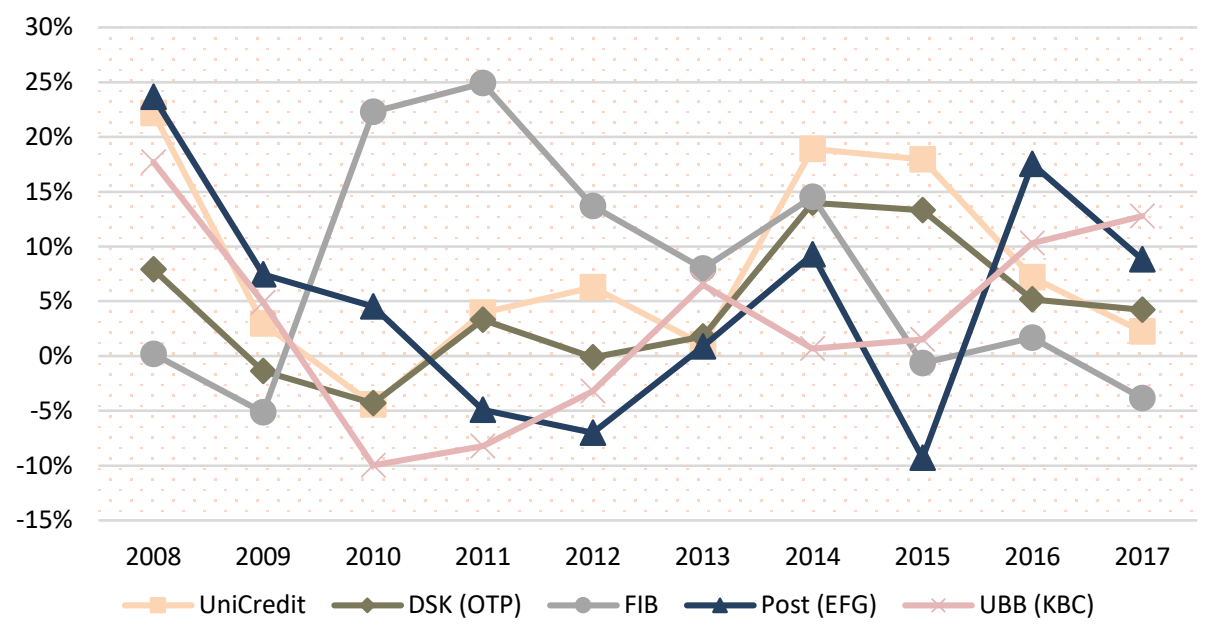

Fig. 3. Dynamics of the deposit portfolio of banks 


\subsection{Dynamics of Returns}

We also study the portfolio returns, their evolution through time and compare the cross-sectional differences between banks, characterize the mean and variation. The spreads over and above Euribor are also examined.

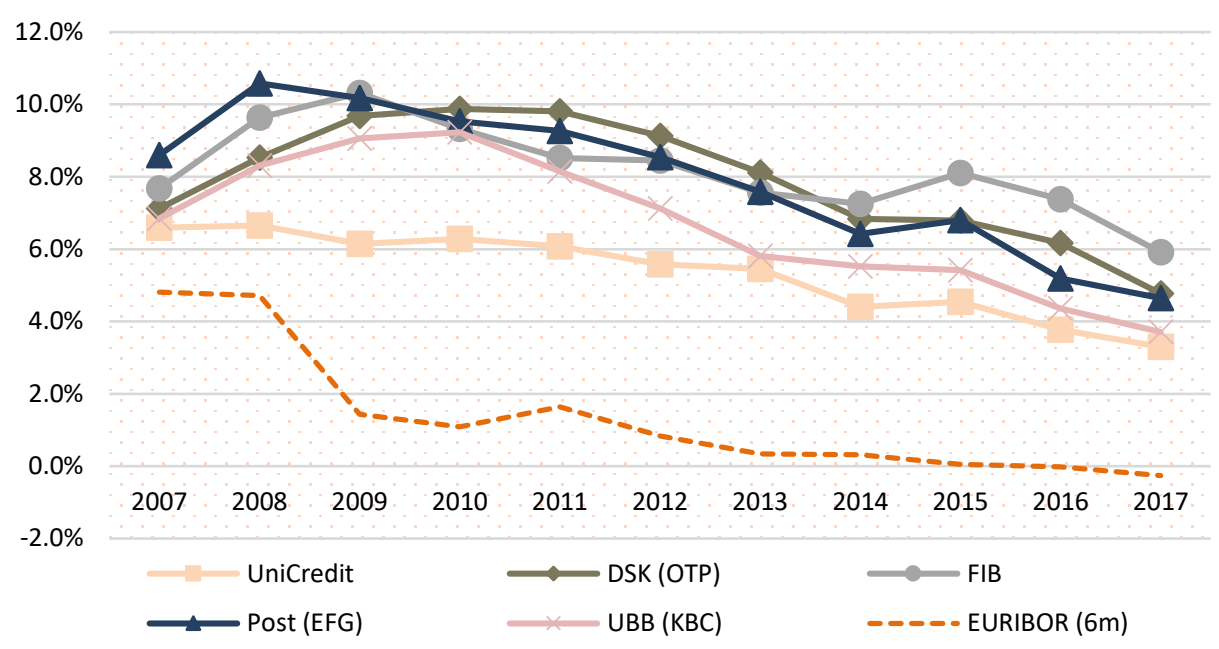

Fig. 4. Interest return on combined loan and bond portfolios of banks versus $6 \mathrm{~m}$ Euribor According to the data, presented on Fig. 4, the greatest values are reported after 2008 when there is already a steady decrease in the yield on combined bond and loan portfolio of banks. The main reason for that is the ECB monetary policy easements and the low interest rates imposed by it. We use $6 \mathrm{~m}$ Euribor as a basis, whose dynamic follows the base interest rate of ECB. The link between Euribor and Bulgarian bank interest rates is reported by Mihailov (2014) to be significant and strong. 


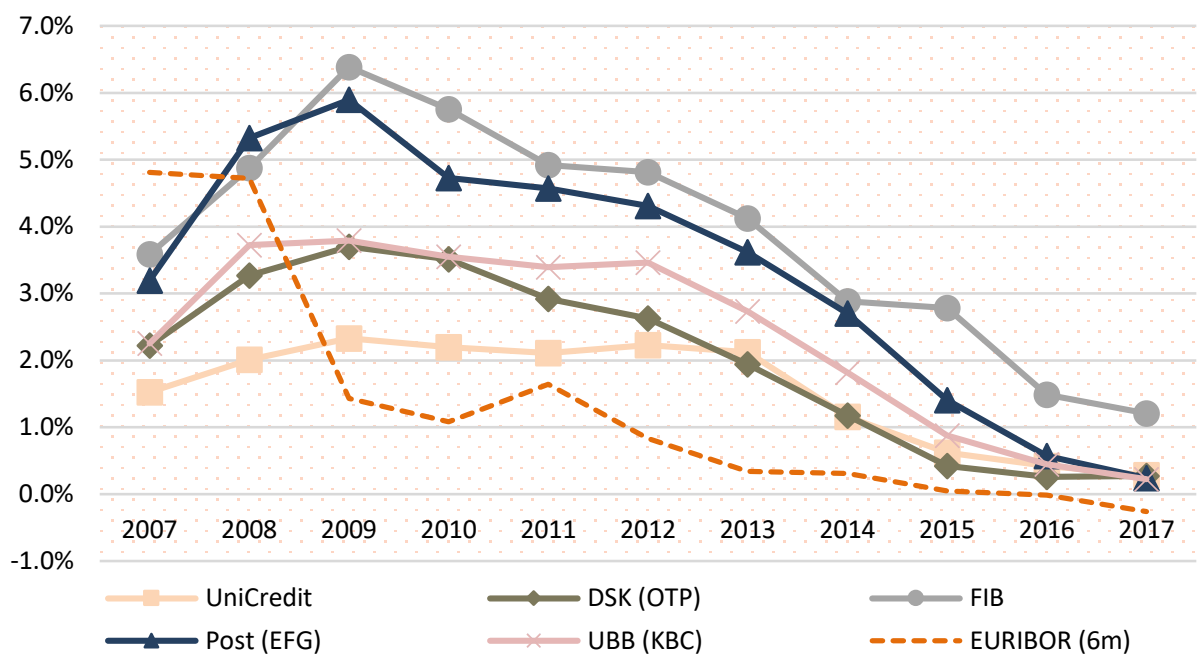

Fig. 5. Interest rates on deposits versus Euribor $6 \mathrm{~m}$

Interest rates on deposits also decreases for the concerned period, reaching nearly $0 \%$ in 2017 . Accounting for inflation of $2 \%$ in 2017 , the real interest rates on deposits were negative. Nevertheless, the deposit base increased. As shown in the figure, the interest rate spread is significantly higher during the crisis and post-crisis period and gradually decreases after 2011 .

\subsection{The non-interest income and costs, their relation to the interest fees}

The evolution and the cross-sectional comparison of the non-interest income of the five banks are presented in Fig.6. There is a well pronounced negative correlation between the interest and non-interest income for all of the banks. This is even more so amplified by the recent decline of interest rates which made all the bank in Bulgaria prop up the pricing of their non-interest services.

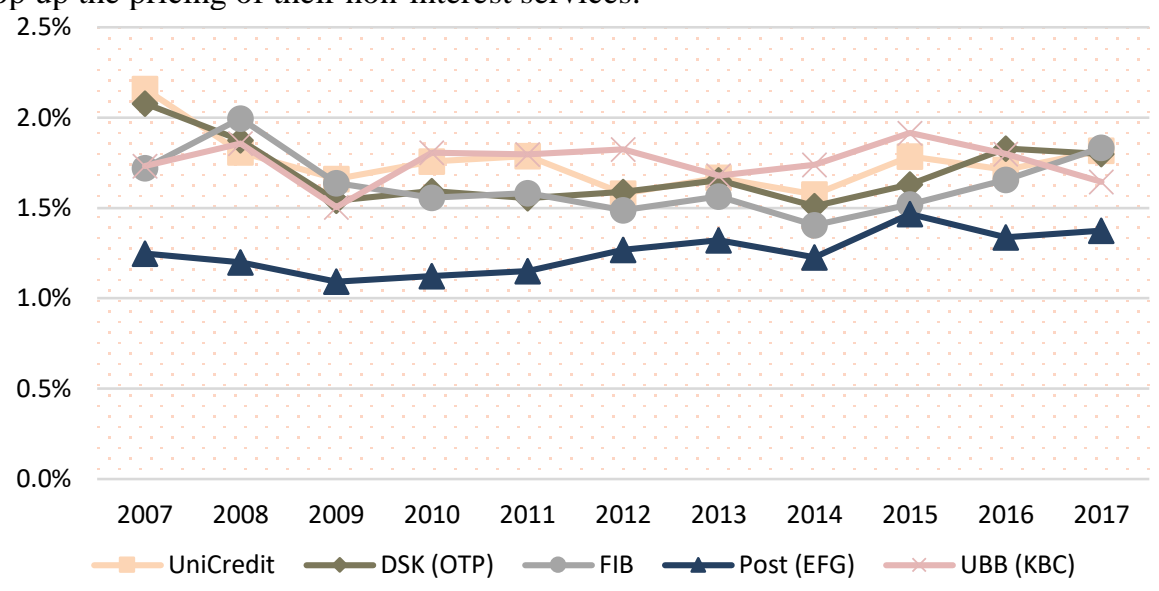


Fig. 6. Non-interest return on assets

In the last three years non-interest return on assets increase, as a compensation for the low interest rates. The values are pretty similar between banks, except Postbank, which register lowest values for the whole period. The dynamics of non-interest expenses, provisions rates and revaluation expenses percentage rates are not presented in the paper because they are steady over the years. Moreover, the non-interest expenses ratio and provision ratio is insignificant (under $0.1 \%$ ). Both groups however tend to magnify during bank and economy-wide crises and have to be modelled stochastically for the purpose of stress-testing.

\subsection{Costs of running a bank}

The general trend of cost-saving cannot be properly captured as the position is aggregated. On one hand nearly all the banks are trimming their branch network running costs. However, the effect of this policy is off-set by the increased marketing expenses. As these are all hurled in one position on the comprehensive income statement, the effect cannot be segregated.

\section{Factor Forecasts, Cost of Capital, Value and Sensitivity}

\subsection{Assumptions regarding factors}

In order to specify the forecasts of the model driving factors we have decided to apply historical averages adjusted for the current positioning in the business and monetary policy cycles. In particular, we assume a long-term growth of the economy of 2.5$3.5 \%$, based on forecast by BNB and ECB. We have taken into account the general policy makers stance of gradually returning interest rates to their long term averages. The factor specifications are provided in the Table 1.

Table 1. Key Driving Factor Specifications

\begin{tabular}{ccl}
\hline Driving Factor & Assumption & Rationale \\
\hline \multirow{2}{*}{ Deposits Growth } & $4.0 \%(2018)$ & Mainly GDP growth driven, no relation to inter- \\
& $2.5 \%(2028)$ & est rates established \\
Loans Growth & $4.0 \%(2018)$ & GDP growth driven in the long run but confi- \\
& $2.5 \%(2028)$ & dence index levels driven in the short term \\
Bonds Growth & $15.0 \%(2018)$ & Serve as store of liquidity and the bonds tend to \\
& $4 \%(2028)$ & grow less when loans accelerate and vice versa \\
Interest Return & $3.6 \%(2018)$ & Euribor growth estimates and mean reversion as- \\
& $6.0 \%(2028)$ & sumption applied \\
Interest Expenses & $0.2 \%(2018)$ & Euribor growth estimates and mean reversion as- \\
& $2.2 \%(2028)$ & sumption applied
\end{tabular}




$\begin{array}{lll}\text { Non-interest Income } & 1.9 \%(2018) & \text { Assumed flat as two opposite effects at play }- \\ & 1.9 \%(2028) & \text { bank strategies and competition }\end{array}$

\subsection{Cost of Capital Estimation}

Amongst the various options we apply the CAPM and specify it according to quotes by Damodaran (Damodaran 2002) as per Copeland (Copeland 1988) for banks. The riskfree rate is based on a long-term Bulgarian government yield to maturity for as of $30 / 06 / 2018$ of $1.3 \%$. Market risk premium is assumed at $4.5 \%$ and a bank financial institution equity beta of 1.00 is applied. This specifies a cost of capital rate of $7 \%$. A country risk premium of $1.2 \%$ is applied as all banks are in a still developing market.

\section{$4 \quad$ Main Observations and Discussion}

Most of the cross-sectional divergence between banks comes from their interest income spreads over and above the 6m EURIBOR used as a benchmark for this analysis. Unicredit maintains stable lower spreads on both lending and deposit side. This has a significant effect on value and is just one example of the sensitivity of valuation to this factor. The values estimates are very sensitive to growth of the loan portfolio and the bonds portfolio. The split of fund placement between bonds and loans is also very important as loans generate significantly higher returns, especially in good times. An important part, although less significant is played by non-interest spreads as banks are trying to increase the share of these. One has to factor in competition from fintech and e-banks and it is therefore prudent to project no increase in the long-run.

Table 2. Valuation Results

\begin{tabular}{lccc}
\hline Bank & DCF Model Estimate & Book Value & Estimate/Book \\
\hline UNICREDIT & $4,772,729$ & $2,853,255$ & 1.67 \\
DSK & $3,707,501$ & $1,548,464$ & 2.39 \\
UBB & $4,084,172$ & $1,301,337$ & 3.14 \\
Post & $2,428,107$ & $1,237,029$ & 1.96 \\
FIB & $1,187,450$ & 929,249 & 1.28 \\
\hline Average & & & 2.06 \\
\hline
\end{tabular}




\section{Conclusion}

We have managed to apply a DCF model for valuation of banks to the 5 largest banks in Bulgaria. In order to specify the forecasts of the value driving factors of the model we have analyzed their historical performance and relation and have applied consensus views for the development of the global, EU and Bulgarian economies. One major assumption of ours is gradual return of the interest rates to their long term average real levels. Another is the continuation of the moderate growth of the EU and Bulgarian economies of 2.5-3\% per annum. Following the identified relation of $2.0 \mathrm{x}$ linear relationship of deposits growth to GDP we have respectively assumed 4.0-4.5\% growth of the deposit portfolio and the loan portfolio of the largest five banks. The valuations of the banks exceed the historical accounting value of capital 2.06 times, which is $40 \%$ higher than the average Value to Book ratios of the banking sector in Europe. The overall conclusion is that the model, when appropriately specified perform satisfactorily and generates meaningful results. Further problems to study are the statistical distributions of the loan losses and provisions.

\section{References}

1. Copeland, T., \& Weston, J. (1988). Financial Theory and Corporate Policy. Boston, MA: Addison-Wesley.

2. Sarastov, Z. (2016) Valuation of Bank Financial Institutions with Stochastic Modelling Under the Discounted Cash Flows Method

3. Damodaran, A. (2002). Investment Valuation. New York: John Wiley \& Sons.

4. Koller, T., Goedhart, M., \& Wessels, T. (2010). Valuation, Measuring and managing the value of companies. Hoboken, New Jersey: John Wiley \& Sons.

5. Mihailov, M., (2017) Loan interest rates in Bulgaria: the role of the monetary policy and the impact of the economic activity.

6. European Money Market Institute, Historical Euribor rates by year, https://www.emmibenchmarks.eu/.

7. Bulgarian National Bank, Financial Supervision Reports Data, 2007 - 2017 